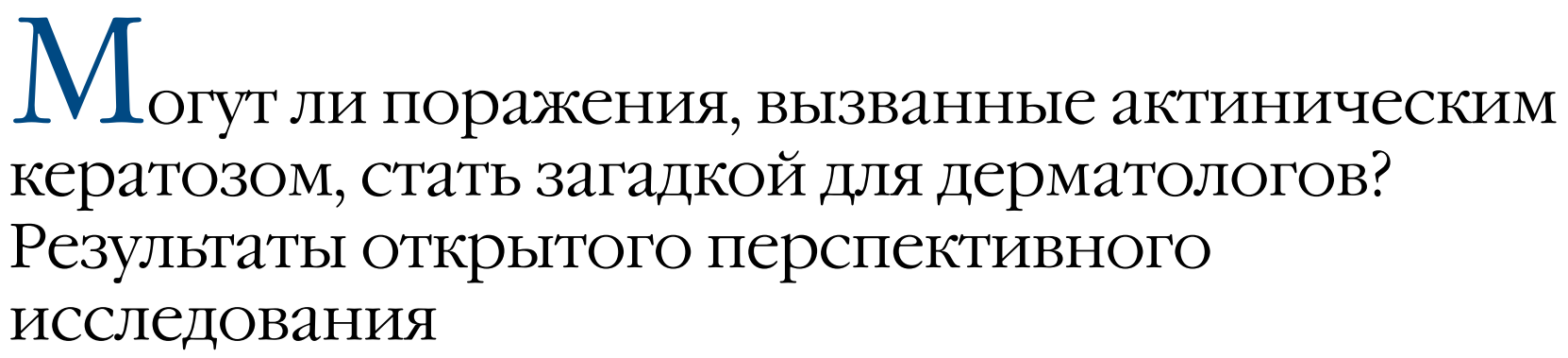

Э. Буйнаускайте ${ }^{1}$, С. Рубинс ${ }^{1}$, А. Рубинс ${ }^{1}$, Ю. Макстиене ${ }^{2}$, Ю. Буйнаускиене ${ }^{3}$

\author{
1 Латвийский университет \\ бульвар Райниса, д. 19, г. Рига, LV-1586, Латвия \\ 2 Клиническая больница Каунасского медицинского университета \\ ул. Эйвеню, д. 2, г. Каунас, LT-50009, Литва \\ ${ }^{3}$ Медицинская академия Литовского университета для наук здравоохранения \\ ул. А. Мицкевича, д. 9, г. Каунас, LT-44307, Литва
}

\footnotetext{
Различные кожные заболевания на лице (базально-клеточная карцинома, актинический кератоз, розацеа, солнечный эластоз и т.д.) могут клинически проявляться как эритематозные пятна, папулы или бляшки. Иногда клинический диагноз таких поражений кожи поставить очень сложно, поскольку их признаки могут частично совпадать или же одно заболевание может мимикрировать под другое, особенно в случае поражения участков, подвергающихся солнечному воздействию. По этой причине гистопатологический анализ остается золотым стандартом диагностики при кожных заболеваниях. Наше исследование показало, что сертифицированные дерматологи очень хорошо диагностируют актинический кератоз (AK) I/II степени на коже лица/головы. В 90,7\% случаев мнения дерматолога и врача-патоморфолога относительно диагноза совпадают, и менее чем в 1\% случаев поражения, диагностированные как AK, оказались злокачественными новообразованиями (базально-клеточная карцинома).

Ключевые слова: актинический кератоз, доброкачественные поражения кожи, гистопатология.
} 


\title{
C \\ an the lesions induced with actinic keratosis become an enigma for dermatologists? Results of an open perspective study
}

E. Bujnauskajte ${ }^{1}$, S. Rubins ${ }^{1}$, A. Rubins ${ }^{1}$, Y. Makstiene ${ }^{2}$, Y. Bujnauskiene ${ }^{3}$

${ }^{1}$ Faculty of Medicine University of Latvia 119 Raina Blvd., Riga, LV-1586, Latvia

${ }^{2}$ Hospital of Lithuanian University of Health Sciences Kauno Klinikos Eiveniu str., 2, LT-50009, Kaunas, Lithuania

${ }^{3}$ Faculty of Medicine Medical Academy, Lithuanian University of Health Sciences

A. Mickevičiaus str., 9, Kaunas, LT-44307, Lithuania

\begin{abstract}
Different face skin diseases (basal cell carcinoma, actinic keratosis, rosacea, solar elastosis, etc.) could clinically manifest itself as erythematic patches, pimples or plagues. It is very hard to make the clinical exclusion in some cases of these diseases since their characters can partially overlap or certain lesion can mimic another one especially in the cases of skin areas affected with sun. Therefore, the histopathological analysis remains the "golden standard" of the dermatological diagnosis at skin diseases. Our study has shown that certified dermatologists detect actinic keratosis (AK) of face/head skin of I/II levels very well. Verdicts of dermatologists and pathomorfologists are congruent on account of diagnosis in $90,7 \%$ cases. Diseases clinically excluded as AK revealed as malignant neoplasms (basal cell carcinoma) in less than $1 \%$ of case lesions.
\end{abstract}

Key words: actinic keratosis, nonmalignant skin lesions, histopathology.

Corresponding author: arubins@apollo.Iv; andris.rubins@|u.Iv. Vestnik Dermatologii i Venerologii 2017; 2: 53_59. 


\section{Введение}

По данным официальной статистики, в Российской Федерации в период с 2003 по 2013 г. уровень заболеваемости злокачественными новообразованиями кожи без учета меланомы увеличился на 27,02\% [1]. При этом во всем мире, начиная с 1939 г., когда была напечатана первая статья, посвященная актиническому кератозу (АК), наблюдается экспоненциальный рост числа публикаций на данную тему. На сегодняшний день АК является одной из самых распространенных причин, по которой пациенты обращаются к дерматологу [2]. Новообразования обнаруживаются у пожилых людей на участках кожи, подвергавшихся длительному солнечному воздействию, например на волосистой части кожи головы, на лбу, переносице, ушных раковинах, щеках, предплечьях, тыльной поверхности кистей рук, и диагноз АК ставится на основании визуального и тактильного осмотра [3]. Для уточнения диагноза может применяться дерматоскопия или конфокальная лазерная сканирующая микроскопия, а к гистопатологическому анализу, являющемуся золотым стандартом диагностики, прибегают только в сомнительных случаях. Дифференциальными диагнозами AK являются опухоли кожи, такие как поверхностная базально-клеточная карцинома, болезнь Боуэна, плоскоклеточная карцинома (SCC), злокачественное лентиго и себорейный кератоз, а также такие дерматозы, как вульгарный псориаз, дерматофития туловища, себорейная экзема и красный плоский лишай. Еще одним важным дифференциальным диагнозом AK, в основном в области голени, является порокератоз, который должен быть подтвержден или исключен по результатам биопсии [3-5]. Тем не менее при диагностировании единичных АК можно столкнуться с трудностями ввиду несовпадения в заключениях дерматологов [6-10] и дерматопатологов [11-12]. Целью нашего исследования стало определение того, способны ли сертифицированные дерматологи с точностью диагностировать АК I и II типов (степени) в области лица и волосистой части кожи головы. В этой связи при включении пациентов с АК в исследование по оценке эффрективности и безопасности фротодинамической терапии (PDT) при AK мы исходили из диагноза АК, поставленного на основе клинических наблюдений и данных гистопатологического анализа (Государственный идентификатор клинических исследований / ClinicalTrials.gov identifier: NCT01541228).

В данной статье описывается только корреляция диагнозов АК, поставленных на основе клинического обследования и гистопатологического анализа, что же касается безопасности и эффективности лечения в долгосрочной перспективе, эта тема будет раскрыта нами в другой публикации.

\section{Материал и методы}

Всем пациентам, отвечающим критериям включения в клиническое исследование, было предложено принять участие во внутрииндивидуальном сравнительном исследовании. Критериям отбора соответствовали пациенты старше 50 лет с клиническим диагнозом, указывающим на наличие, по крайней мере, двух очагов негиперкератозного не подвергавшегося лечению АК диаметром от 0,5 см до $3 \mathrm{~cm}$, расположенных в области лица/волосистой части кожи головы, где нет проявлений иных кожных заболеваний. Очаги AK должны соответствовать I или II клинической степени по Ольсену [13].

Два сертифицированных специалиста-дерматолога провели осмотр кожи пациентов и идентифицировали все случаи AK I/II типа в области головы/волосистой части кожи головы. В случае разногласий между этими двумя специалистами по поводу диагноза АК или по поводу констатируемой клинической стадии AK для консультации приглашался третий дерматолог, и окончательный диагноз ставился после трехстороннего обсуждения. Все пораженные участки кожи маркировались и фотографировались для ведения фотодокументации.

На всех подозрительных участках пораженной кожи, представлявших собой классические образцы АК | или || степени, биопсийное исследование материала которых обычно не требуется, была проведена 3,5-миллиметровая пункционная биопсия. Образцы тканей с АК были фиксированы в 10\% буфрерном формалине, обработаны с применением рутинных гистопатологических методов и окрашены гематоксилином и эозином. Далее срезы тканей оценивались двумя сертифицированными дерматологами. Сомнительные случаи разрешались в результате анализа и обсуждений, в процессе которых применялся двойной микроскоп.

\section{Статистический анализ}

Вся статистическая обработка данных осуществлялась с помощью статистической компьютерной программы SPSS («статистический пакет для социальных наук») для версии 18.0 Windows.

Степень единодушия двух сертифицированных медиков в отношении идентифицируемых ими и связанных друг с другом медицинских понятий рассчитывалась с использованием каппа-статистики [14].

Прогностическая ценность положительного результата рассчитывалась на основе диагнозов, поставленных после сравнения клинических диагнозов АК с гистопатологическими, имевших статус заключительных диагнозов.

\section{Результаты}

В начальной фразе клинического испытания принимали участие 48 пациентов с 2-5 кератотическими 
очагами в области головы/волосистой части кожи головы, и всего в этой группе было проведено 140 пункционных биопсий.

Клинический диагноз и результаты гистопатологического анализа совпали в случае 90,7\% (127/140) всех образцов пораженных участков кожи, подвергнутых биопсии.

Среди них 2,9\% (4/140) оказались участками АК с поражениями смешанного характера, содержащими также клеща Demodex folliculorum и грибковые споры. Прогностическая ценность положительного результата для клинического диагноза АК, поставленного дерматологом, составляла 90,7\% (95\% Cl: 84,37-94,78). Доброкачественные изменения были обнаружены в 8,6\% (12/140) случаев, а злокачественные новообразования кожи были констатированы только в 0,7\% (1/140) всех случаев (подробные данные представлены в таблице, на рис. 1, 2).

Коэффициент каппа, превышающий величину 0,81, рассматривался в качестве практически идеального: он составлял 0,92 среди дерматологов и 0,90 среди дерматопатологов.

\section{Обсуждение}

Количество визитов в кабинет дерматолога, в результате которых ставятся диагнозы АК и немеланомный рак кожи, продолжает расти [1, 7]. Наше исследование свидетельствует о том, что сертифицированные дерматологи очень успешно диагностируют AK I/II степени с локализацией в области лица/волосистой части кожи головы, при этом диагнозы дерматологов и дерматопатологов почти полностью совпадают.

Прогностическая ценность положительного результата показывает вероятность того, что пациент действительно страдает АК, если очаг поражения диагностируется клинически. Результаты нашей работы соответствуют выводам других исследователей, доказывающих, что прогностическая ценность положительного результата (ПЦПР), отражающая способность дерматологов диагностировать АК, колеблется между 74 и 94\% [15-17].

Вероятность столь большого разрыва между группами объясняется, возможно, тем, насколько опытен дерматолог, а также локализацией очага поражения. В исследовании, в котором прогностическая ценность положительного результата (ПЦПР) составляла 74\%, осмотр пациентов с пораженными участками кожи проводился не только сертифицированными дерматологами, но также врачами-ординаторами (специализирующимися в области дерматологии) и поражения на коже рук также учитывались [16]. Однако в тех исследованиях, где ПЦПР была выше 90\%, дигностика пораженных участков кожи проводилась только сертифицированными дерматологами, при этом обследованные очаги поражения были локализованы только на лице и волосистой части кожи головы [17-19].

Для типичной клинической картины АК характерны чешуйчатые (чешуеобразные) или кератозные очажки (пятна), папулы или бляшки на эритематозной базе; при пальпации обнаруживается шершавость кожи, диагностированным по результатам клинического обследования и гистопатологического анализа

Тип очагов поражения

\section{Очаги поражения}

фактическое число в процентах

Нераковые (доброкачественные) новообразования

\begin{tabular}{|c|c|c|}
\hline Солнечный эластоз & 2 & 1,5 \\
\hline Розацеа & 3 & 2,1 \\
\hline Раздраженный (гиперкератотический) себорейный кератоз/Irritated seborrheic keratosis & 3 & 2,1 \\
\hline Подострый пузырьковый дерматит/Subacute spongiotic dermatitis & 4 & 2,9 \\
\hline \multicolumn{3}{|l|}{ Раковые (злокачественные) новообразования } \\
\hline Актинический кератоз & 123 & 87,7 \\
\hline Очаги AK с поражениями смешанного характера, содержащими также Demodex folliculorum & 2 & 1,5 \\
\hline Очаги АK с поражениями смешанного характера, содержащими также грибковые споры & 2 & 1,5 \\
\hline Общее количество случаев АК & 127 & 90,7 \\
\hline Базально-клеточная карцинома & 1 & 0,7 \\
\hline Всего случаев & 140 & 100,0 \\
\hline
\end{tabular}




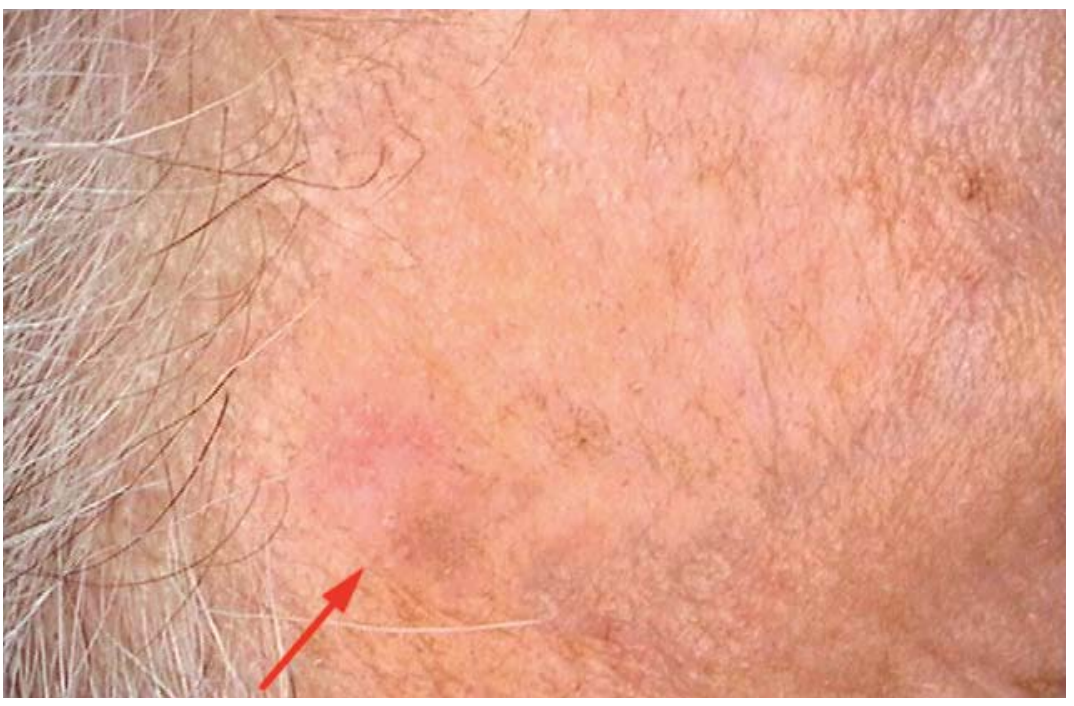

a

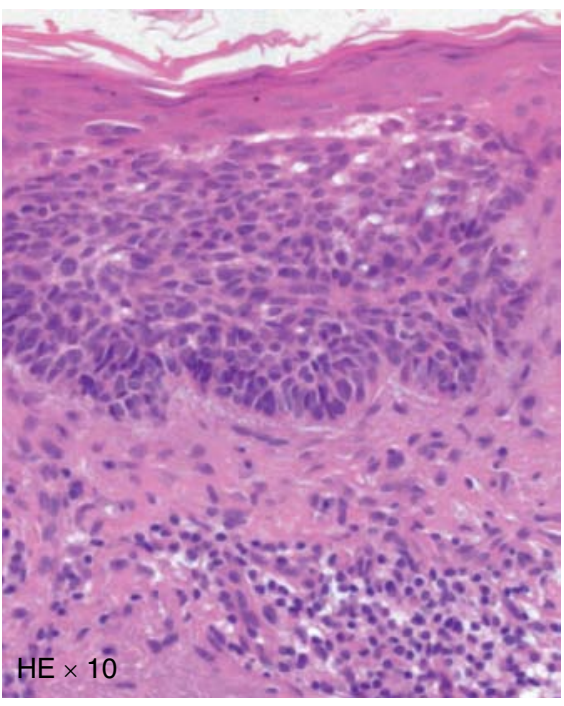

6

Рис. 1. Фотографии клинической картины (а) и результатов гистологического анализа (б) пораженного участка на лице (клинически диагностирован актинический кератоз, оказавшийся по результатам гистологии поверхностной базально-клеточной карциномой)

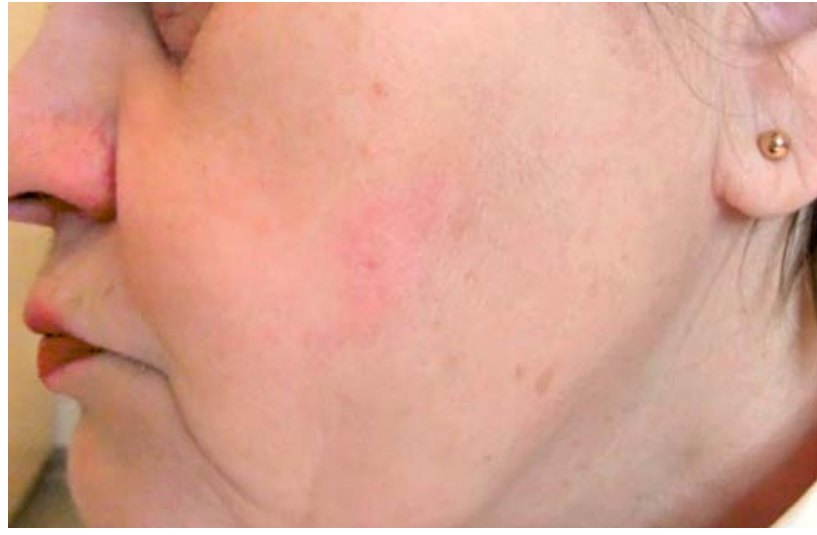

a

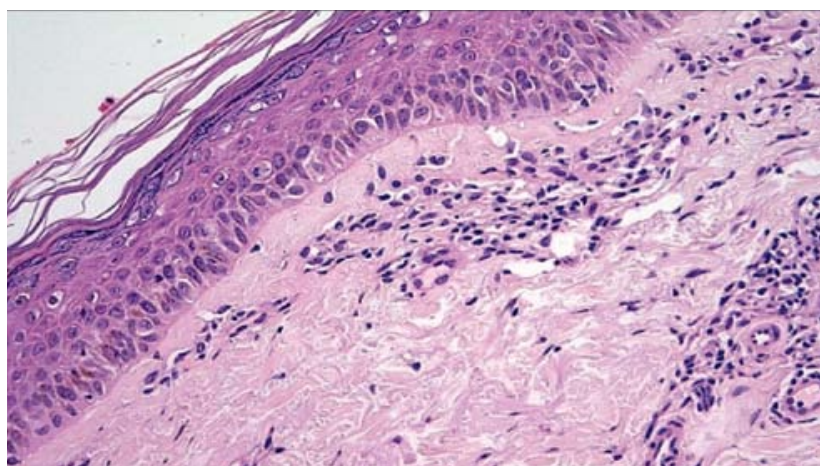

B

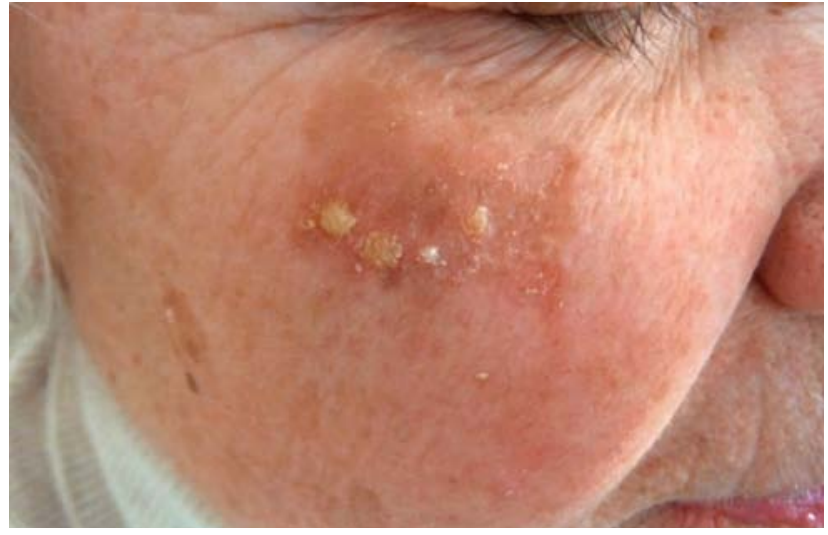

6

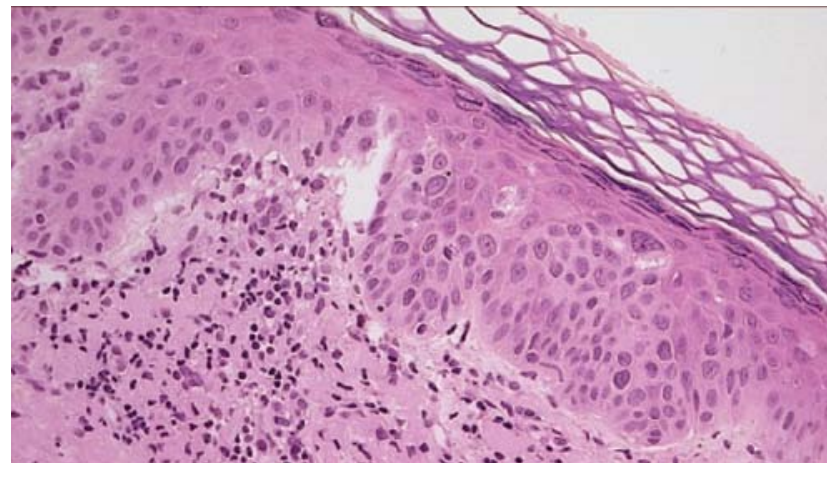

$\Gamma$

Рис. 2. Фотограсии клинической картины $(a, 6)$ и результатов гистологии $(B, \Gamma)$ пораженных участков кожи лица (клинический диагноз АК, подтвержденный и гистологически) 
напоминающая наждачную бумагу [20]. Очаги поражения кожи могут быть единичными или множественными и сливающимися. Пораженные участки обычно имеют тот же цвет, что и окружающая их кожа, но могут также представлять собой розовые, красные или коричневатые пятна, папулы или бляшки [21]. Кожа вокруг очагов поражения может носить на себе такие следы хронических фотоповреждений, как телеангиэктазия, дисхромия, эластоз и морщины [22]. Несмотря на то что диагноз АК обычно устанавливается клинически, поражения кожи другой этиологии могут быть ошибочно приняты за АK, и, наоборот, бывает, что АK принимают за другое заболевание [18]. Дифференциальный диагноз включает в себя различные повреждения кожных покровов, которые могут иметь цвет от нормального (цвет кожи) до коричневатого; проявляться как в виде макул, так и бляшек; быть единичными очажками или множественными и слившимися.

Результаты нашего исследования поддерживают выводы S. Thompson и соавт.,1993 [23], согласно которым наиболее часто устанавливаемым ошибочным диагнозом был подострый пузырьковый дерматит (subacute spongiotic dermatitis). Клинически это заболевание рассматривается как экзема, которая является распространенным поражением кожи с множественными клиническими проявлениями, однако гистологический анализ показывает в этом случае спонгиотическую тканевую реакцию. Клиническая картина при AK II степени описывается как папула или бляшка с шершавой гиперкератозной поверхностью от розового до красного цвета [24]. Таким образом, дифференциальный диагноз АК может включать в себя экзему и себорейный кератоз, что нередко встречалось как в нашем, так и в других исследованиях $[15,16,19,25]$.

Клиническая картина при АК I степени описывается как очаг с плоской розовой макулой на поврежденной солнцем коже; пятнистое поражение кожи различной формы и цвета; отсутствие шершавости или гиперкератоза [24]. Очаги поражения локализова- ны на поврежденной солнцем коже, и иногда их могут ошибочно принимать за обычный солнечный эластоз $[15,19,23]$. Такой ложный диагноз, как розацеа, не фигурировал в других исследованиях, однако в работе S. Thompson и соавт.,1993 [23], в качестве диагноза упоминается гемангиома.

В отличие от других исследователей [16, 19, 25, 26], мы не сталкивались с таким ложным диагнозом, как плоскоклеточная карцинома, и нами был зафиксирован только один случай ложного диагноза - базально-клеточной карциномы. Возможно, это объясняется тем, что мы исключили АК III степени из нашего анализа и учли предположение J. Whited и соавт. [9] относительно того, что дерматологи со значительно большей точностью диагностируют злокачественные новообразования кожи, когда при физическом осмотре пациента учитываются данные анамнеза.

Данная работа носит ограниченный характер ввиду относительно небольшого размера выборки и включения в анализ случаев АК только легкой и умеренной степени с локализацией в области лица/волосистой части кожи головы. Тем не менее это исследование доказывает, что сертифицированные специалистыдерматологи очень успешно диагностируют AK I/II степени, хотя в сомнительных случаях золотым стандартом диагностики остается гистопатологический анализ.

\section{Выводы}

Наше исследование показало, что сертифицированные дерматологи очень успешно диагностируют актинический кератоз I/II степени с локализацией в области лица/волосистой части кожи головы. Клинический диагноз, установленный отдельно дерматологами и врачами-патоморфологами, имеющими специализацию в области дерматологии, совпал в 90,7\% случаев, и менее $1 \%$ поражений кожи, диагностированных как АК, оказались злокачественными новообразованиями (базально-клеточной карциномой). Для подтверждения диагноза АК необходимо проводить гистопатологическое исследование.

\section{Литература}

1. Кубанова А.А., Кубанов А.А., Кондрахина И.Н., Грибанов Н.В. Фотодинамическая терапия поверхностной формы базально-клеточного рака кожи и актинического кератоза с топическим применением метиламинолевулинат. Вестн дерматол венерол 2015; (4): 105-112. Kubanova A. A., Kubanov A. A., Kondrahina I. N., Gribanov N. V. Fotodinamicheskaya terapiya poverhnostnoj formy bazal'no-kletochnogo raka kozhi i aktinicheskogo keratoza $s$ topicheskim primeneniem metilaminolevulinat. Vestn dermatol venerol 2015; (4): 105112.

2. Sellheyer K., Bergfeld W. F. Differences in biopsy techniques of actinic keratoses by plastic surgeons and dermatologists: a histologically controlled pilot study. Arch Dermatol 2006; 142 (4): 455-9.
3. Strunk T., BraathenL. R., SzeimiesR.-M. Actinic keratoses - a systemic review. Вестник дерматологии и венерологии 2014; (5): $32-41$.

4. Tlish M.M., Katkhanova O.A., Naatij J.Y., Popovskay E. B., Sicheva N. L. Actinic reticuloid: case study. Вестник дерматологии и венерологии 2014; (3): 105-109. 
5. Znamenskaya L. F., Chikin V.V., Kappusheva I. A., Kondrasheva V. V. Disseminated superficial actinic porokeratosis in patient suffering from plaque psoriasis: a case report. Vestnik Dermatologii i Venerologii 2015; 5: 91—96.]

6. Whited J.D., Horner R. D., Hall R.P., Simel D. L. The influence of history on interobserver agreement for diagnosing actinic keratoses and malignant skin lesions. J Am Acad Dermatol 1995; 33: 603—7.

7. Weinstock M. A., Bingham S. F., Cole G. W. et al. Reliability of counting actinic keratoses before and after brief consensus discussion: the VA topical tretinoin chemoprevention (VATTC) trial. Arch Dermatol 2001; 137 (8): 1055—8.

8. Harvey I., Frankel S., Marks R. et al. Nonmelanoma skin cancer and solar keratoses. I. Methods and descriptive results of the South Wales Skin Cancer Study. Br J Cancer 1996; 74: 1302-7.

9. Whited J. D., Hall R.P., Simel D. L., Hormer R.D. Primary care clinicians' performance for detecting actinic keratoses and skin cancer. Arch Intern Med 1997; 157: 985-90.

10. Leffell D. J., Chen Y-T., Berwick M., Bolognia J. L. Interobserver agreement in a community skin cancer screening setting. J Am Acad Dermatol 1993; 28: 1003-5.

11. Jagdeo J., Weinstock M. A., Piepkorn M. et al. Reliability of the histopathologic diagnosis of keratinocyte carcinomas. J Am Acad Dermatol 2007; 57(2): 279—84.

12. Davis D. A., Donahue J.P., Bost J. E., Horn T.D. The diagnostic concordance of actinic keratosis and squamous cell carcinoma. J Cutan Pathol 2005; 32(8): 546-51.
13. Olsen E. A., Abernathy L., Kulp-Shorten C. et al. A double blind, vehicle controlled study evaluating masoprocol cream in the treatment of actinic keratoses of the head and neck. J Am Acad Dermatol 1991; 24: 738-43.

14. Cohen J. A coefficient of agreement for nominal scales. Educ and Psychol Meas 1960; 20: 46.

15. Marks R., Rennie G., Selwood T. S. Malignant transformation of solar keratoses to squamous cell carcinoma. Lancet 1988; 1: 795-7.

16. Venna S. S., Lee D., Stadecker M. J., Rogers G. S. Clinical recognition of actinic keratoses in a high-risk population: how good are we? Arch Dermatol 2005; 141: 507-9.

17. Tirado-Sánchez A., Ponce-Olivera R. M., Sierra-Téllez D. Recognition of actinic keratosis. A retrospective biopsy study of the clinical diagnostic accuracy by primary care physicians compared with dermatologists. Experience in Mexico. Our Dermatol Online 2011; 2 (4): $175-80$.

18. Holmes C., Foley P., Freeman M., Chong A. H. Solar keratosis: Epidemiology, pathogenesis, presentation and treatment. Austral $\mathrm{J}$ of Derm 2007; 48: 67-76.

19. Ehrig T., Cockerell C., Piacquadio D. et al. Actinic keratoses and the incidence of occult squamous cell carcinoma: a clinical, histopathologic correlation. Dermatol Surg 2006; 32: $1261-5$.
20. Werner R. N., Stockfleth E., Connolly S. M., Correia 0., Erdmann R., Foley P. et al. Treatment of Actinic Keratosis - International League of Dermatological Societies in cooperation with the European Dermatology Forum - Short version. JEADV 2015, 29, 2069-2079.

21. Roewert-Huber J., Stockfleth E., Kerl H. Pathology and pathobiology of actinic (solar) keratosis — an update. Br J Dermatol 2007; 157 (Suppl. 2): 18-20.

22. Schmitt J. V., Miot H. A. Actinic keratosis: a clinical and epidemiological revision. An Bras Dermatol 2012; 87: 425—434.

23. Thompson S. C., Jolley D., Marks R. Reduction of solar keratoses by regular sunscreen use. N Engl J Med 1993; 329: 1147—51.

24. Cockerell C. J. Histopathology of incipient intraepidermal squamous cell carcinoma ("actinic keratosis"). J Am Acad Dermatol. 2000 Jan; 42 (1 Pt 2): 11-7

25. Carag H. R., Prieto V.G., Yballe L. S., Shea C.R. Utility of step sections: demonstration of additional pathological findings in biopsy samples initially diagnosed as actinic keratosis. Arch Dermatol 2000; 136(4): 471—5.

26. Heal C. F., Weedon D., Raasch B.A. et al. Agreement between histological diagnosis of skin lesions by histopathologists and a dermato-histopathologist. Int J Dermatol 2009; 48 (12): 1366-9.

об авторах:

Э. Буйнаускайте - д.н., профрессор кафедры дерматовенерологии Латвийского университета

С. Рубинс - Д.н., врач, Латвийский университет

А. Рубинс - д.н., профрессор, зав. кафедрой дерматовенерологии кафедры дерматовенерологии Латвийского университета

Ю. Макстиене - д.н., врач клинической больницы Каунасского медицинского университета

Ю. Буйнаускиене - д.н., профессор, врач, Медицинская академия Литовского университета для наук здравоохранения

\section{Источник финансирования}

Частичная финансовая помощь для закупки 5-аминолевулиновой кислоты получена в качестве гранта Каунасского медицинского университета (с 2011 - Медицинской академии при Литовском университете наук о здоровье)

\section{Конфликт интересов}

Авторы заявляют об отсутствии потенциального конфрликта интересов, требующего раскрытия в данной статье 